\title{
Eligibility for interventions, co-occurrence and risk factors for unhealthy behaviours in patients consulting for routine primary care: results from the Pre-Empt study
}

Elizabeth Randell ${ }^{1 *}$, Timothy Pickles' ${ }^{1}$ Sharon A. Simpson ${ }^{2}$, Clio Spanou ${ }^{3}$, Jim McCambridge ${ }^{4}$, Kerenza Hood $^{1}$ and Christopher C. Butler ${ }^{5}$

\begin{abstract}
Background: Smoking, excessive drinking, lack of exercise and a poor diet remain key causes of premature morbidity and mortality globally, yet it is not clear what proportion of patients attending for routine primary care are eligible for interventions about these behaviours, the extent to which they co-occur within individuals, and which individuals are at greatest risk for multiple unhealthy behaviours. The aim of the trial was to examine 'intervention eligibility' and co-occurrence of the 'big four' risky health behaviours - lack of exercise, smoking, an unhealthy diet and excessive drinking - in a primary care population.
\end{abstract}

Methods: Data were collected from adult patients consulting routinely in general practice across South Wales as part of the Pre-Empt study; a cluster randomised controlled trial.

After giving consent, participants completed screening instruments, which included the following to assess eligibility for an intervention based on set thresholds: AUDIT-C (for alcohol), HSI (for smoking), IPAQ (for exercise) and a subset of DINE (for diet). The intervention following screening was based on which combination of risky behaviours the patient had. Descriptive statistics, $x 2$ tests for association and ordinal regressions were undertaken.

Results: Two thousand sixty seven patients were screened: mean age of 48.6 years, $61.9 \%$ female and $42.8 \%$ in a managerial or professional occupation. In terms of numbers of risky behaviours screened eligible for, two was the most common (43.6\%), with diet and exercise (27.2\%) being the most common combination. Insufficient exercise was the most common single risky behaviour (12.0\%). $21.8 \%$ of patients would have been eligible for an intervention for three behaviours and $5.9 \%$ for all four behaviours. Just $4.5 \%$ of patients did not identify any risky behaviours. Women, older age groups and those in managerial or professional occupations were more likely to exhibit all four risky behaviours.

Conclusion: Very few patients consulting for routine primary care screen ineligible for interventions about common unhealthy behaviours, and most engage in more than one of the major common unhealthy behaviours. Clinicians should be particularly alert to opportunities to engaging younger, non professional men and those with multi-morbidity about risky health behaviour.

Trial registration: ISRCTN22495456

Keywords: Screening, Health behaviours, Primary care, Physical activity, Diet, Smoking

\footnotetext{
* Correspondence: randelle@cardiff.ac.uk

${ }^{1}$ South East Wales Trials Unit, Centre for Trials Research, Cardiff University, 7th floor Neuadd Meirionnydd, Heath Park, Cardiff CF14 4YS, UK

Full list of author information is available at the end of the article
} 


\section{Background}

'Risky' health behaviours such as smoking, excessive drinking, lack of exercise and a poor diet remain key causes of premature morbidity and mortality globally [1]. The recent Global Burden of Disease study highlights that cancer and heart disease have now become the dominant causes of death and disability worldwide and that non-communicable diseases are increasing among adults [2]. The World Health Organisation (WHO) report that $61 \%$ of cardiovascular deaths and over three quarters of the world's ischaemic heart disease (the leading cause of death) can be accounted for by just 8 risk factors - alcohol use, tobacco use, high blood pressure, high body mass index, high cholesterol, high blood glucose, low fruit and vegetable intake, and physical inactivity [2]. These behaviours could be attributed to an unhealthy lifestyle the consequences of which account for roughly $70 \%$ of health care expenditure [3]. The terminology used in current literature for these behaviours varies but for the purposes of this paper, the phrases 'risky health behaviours' and 'unhealthy behaviours' will be used alike.

In 2014 the Welsh Health Survey reported that $21 \%$ of adults smoked, $42 \%$ of adults admitted to drinking above the guidelines on at least one day in the past week, including $26 \%$ who reported drinking more than twice the daily guidelines (sometimes termed binge drinking) and just $29 \%$ met the guidelines for physical activity [4]. Additionally $58 \%$ of adults were classed as overweight or obese. A key issue is that these unhealthy behaviours are known to often co-occur [5], for example, smokers typically have poorer diets, are less physically active, and consume more alcohol than non-smokers [6-8]. This increases not only the risk of disease [9] but is also a challenge for those trying to intervene [10]. In addition, health behaviours have also been shown to cluster in populations [11] with men, younger age groups and people of low socioeconomic status and education being more likely to engage in multiple risky health behaviours [12-15].

General practice in the U.K. can offer an ideal opportunity to identify beneficial lifestyle changes as over $80 \%$ of patients attend consultations annually [16]. Patients expect practitioners to discuss health behaviours and be a reliable source of advice [17]. Given that patients attend an average of 5.5 consultations per year [18], GPs and practice nurses have the unique opportunity of being able to intervene across a range of behaviours in the same individual over time. However, opportunity is only part of the equation. With busy schedules, clinicians need to know how to use these opportunities to best effect. Barriers to achieving this lie in identifying who might most benefit from intervention (screening) and having the necessary skills and confidence to tackle these issues (intervention) [19].

Feedback from primary care practitioners highlights the need for more explicit guidance regarding screening and intervention for health behaviours and especially better methods of recognising multiple behavioural risks [20]. Routine screening for risky lifestyle behaviours in all patients may not be feasible, so targeting high risk groups - such as those with relevant health conditions such as hypertension, diabetes or particular populations [21] - may effectively assess and highlight those who would benefit from early intervention or referral to other services before more serious chronic conditions emerge [2].

Highlighting the risks associated with an unhealthy lifestyle is an important way of pre-empting health needs before they arise, equipping patients with resources that preserve future health and thus reducing possible disease risks [22]. This way of improving population health, although only part of an overall strategy, has been associated with substantial health benefits [22, 23]. Screening patients for risky health behaviours is therefore an important step in anticipatory care. Instead of reacting to the presentation of single risky health behaviours or problems resulting from them, anticipatory care suggests that if it is known that other risky behaviours are likely to follow, they could be addressed at the same time. Recent work by The King's Fund [16] also confirms the need for a 'holistic approach to policy and practice' and shifting focus to tackling multiple health behaviours at once rather than single ones.

The aim of this study is to use data from the Pre-Empt trial to examine the numbers of patients consulting for routine care who would be eligible for an intervention about unhealthy behaviours according to current recommendations, and the co-occurrence of the big four risky health behaviours - lack of exercise, smoking, an unhealthy diet and excessive drinking - in a primary care population in order to help inform best practice in screening and identification of patterns of health behaviours.

\section{Method}

The study was approved by the Multi-centre Research ethics Committee (MREC, 07/MRE09/11) and all Local Health Boards (LHBs) in Wales.

\section{Study design}

Data were collected as part of the Pre-Empt study; a cluster randomised controlled trial with randomisation at the General Practice level [24].

\section{Participants}

A total of 2067 patients who consulted primary care clinicians at 27 general practices across South Wales were 
screened to take part in the Pre-empt trial by completing a baseline questionnaire. Practices were a mixture of rural and urban with varying list sizes. Participants were consulting for a wide range of acute and chronic concerns, were aged 18 years or over and able to provide informed consent. The inclusion criteria to be eligible for the Pre-Empt trial was to screen above/below set cut points for at least one of the four risky health behaviours. There were no specific exclusion criteria, other than that the patient had to be able to understand and comply with the requirements as laid out in the study information sheet which meant that those who were unable to complete the questionnaires in English were excluded. In addition, after a brief discussion, the clinician (in both intervention and control practices) and the patient might decide that it would not be beneficial for the patient to participate in the trial.

\section{Procedure}

Patient recruitment took place in practices in two intensive, one-week periods. During the recruitment week, patients entering the practice to see a clinician taking part in the study that day were given a flyer by the practice receptionist after booking in for their appointment. The flyer contained brief information about the study and invited the patient to speak with the researchers. If they were then happy to talk gain further information, the researchers then gave the patient a more detailed information sheet, discussed the study, answered any questions and took consent. Patients were then asked to self-complete a short baseline questionnaire which included screening instruments for assessing smoking [25], risky drinking [26], physical activity [27], and dietary behaviour [28, 29].

The screening instruments contained in the baseline questionnaire included;

- A subset of the Dietary Instrument for Nutrition Evaluation (DINE) measuring average fat and fibre intake along with a two item fruit and vegetable question [28, 29]. Patients screened positive for diet if they did not consume at least five portions of fruit and vegetables a day or ate three or more portions of high fat foods per week;

- The three item Alcohol Use Disorders Identification Test - Consumption Scale (AUDIT-C) [26]. This is a 3 item alcohol screen which asks about number and frequency of drinks consumed. A score of more than 3 for women or more than 4 for men screened positive;

- The Heaviness of Smoking Index (HSI) [25]. This 2 item screen asks how soon after waking they have their first cigarette and how many cigarettes an individual smokes per day. Any patient who smoked screened positive;
- The International Physical Activity Questionnaire (IPAQ short form) [27]. This asks about levels of physical activity in a 'usual week'. If patients reported doing less than the recommended $30 \mathrm{~min}$ of vigorous or moderate physical activity five times a week screened positive for exercise.

The screening cut points were chosen specifically for the Pre-Empt trial and reflected threshold levels for each of the health behaviours which could trigger intervention in UK general practice. After each patient had completed the questionnaire, the researchers scored the measures and gave each patient a summary sheet identifying which risky behaviour they exceeded the threshold for to take pass to their GP in their appointment. As far as possible, patients were encouraged to complete any questions missed.

\section{Statistics}

Descriptive statistics, $\chi^{2}$ tests for association and ordinal regressions were undertaken in IBM SPSS Statistics 20. Ordinal regressions (using a Cauchit link function due to underlying normality of the latent variable) were undertaken with number of risky behaviours individuals screened eligible for as the dependent variable (i.e. $0,1,2,3$ or 4 risky behaviours), and the following used as predictors:

1. Age;

2. Gender;

3. Marital status (as dichotomous Married/cohabiting vs. the rest variable);

4. Socio-economic classification (as dichotomous Managerial/Professional Occupation vs. the rest variable);

5. Number of Health Conditions [0 to 11]) based on asking patients about heart disease, diabetes, depression, stroke, arthritis, hypertension, high cholesterol, asthma, COPD, backache.

Tests of parallel lines were undertaken to check the proportionality assumption of these models and all were found to be valid.

The significance level was set at $\alpha=0.05$.

\section{Results}

\section{Demographics}

A total of 2802 patients were approached to take part in the study of which 2067 (73.8 \%) consented and completed a baseline questionnaire. There were missing data for 1 participant.

Mean (SD) age was 48.6 (40.48) years for women and 54.9 (28.17) years for men [Table 1], with 787 (38.1\%) males and 1279 (61.9 \%) females (and one gender not recorded, excluded). The majority of patients were married or cohabiting (63.3\%) and had managerial or 
Table 1 Demographics and Socio-economic classification of participants

\begin{tabular}{|c|c|c|c|c|c|}
\hline \multirow[b]{2}{*}{ Demographics } & \multicolumn{2}{|c|}{ Male $(N=787)$} & \multicolumn{2}{|c|}{ Female $(N=1279)$} & \multirow{2}{*}{$\begin{array}{l}\text { Overall }(N=2066) \\
\text { Mean }\left(S D^{\mathrm{a}}\right) \text { or } \%\end{array}$} \\
\hline & $\bar{N}$ & Mean $\left(\mathrm{SD}^{\mathrm{a}}\right)$ or $\%$ & $\bar{N}$ & Mean $\left(\mathrm{SD}^{\mathrm{a}}\right)$ or $\%$ & \\
\hline Age (years) & 674 & $54.9(28.17)$ & 1100 & $48.6(40.48)$ & $51.0(49.90)$ \\
\hline \multicolumn{6}{|l|}{ Marital Status (\%'s based on 1781 responses): } \\
\hline Single & 116 & 17.1 & 222 & 20.1 & 19.0 \\
\hline Married/cohabiting & 463 & 68.3 & 665 & 60.3 & 63.3 \\
\hline Divorced & 54 & 8.0 & 103 & 9.3 & 8.8 \\
\hline Widowed & 45 & 6.6 & 113 & 10.2 & 8.9 \\
\hline \multicolumn{6}{|l|}{ Socio-economic Classification ${ }^{\mathrm{b}}$ (\%'s based on 1781 responses): } \\
\hline Managerial and Professional Occupations & 231 & 37.9 & 428 & 46.0 & 42.8 \\
\hline Immediate Occupations & 23 & 3.8 & 197 & 20.1 & 13.6 \\
\hline Small Employers and Own Account Workers & 118 & 19.4 & 73 & 7.8 & 12.4 \\
\hline Lower Supervisory and Technical Occupations & 105 & 17.2 & 63 & 6.8 & 10.9 \\
\hline Semi-routine and Routine Occupations & 132 & 21.7 & 180 & 19.3 & 20.3 \\
\hline Self reported health condition (\%'s based on 1540 responses) & N & $\%$ & $\mathrm{~N}$ & $\%$ & $\%$ \\
\hline Other & 187 & 27.5 & 333 & 30.2 & 29.2 \\
\hline Backache & 180 & 26.5 & 332 & 30.1 & 28.7 \\
\hline Arthritis & 155 & 22.8 & 270 & 24.5 & 23.8 \\
\hline Hypertension & 163 & 24.0 & 218 & 19.7 & 21.4 \\
\hline High Cholesterol & 160 & 23.6 & 207 & 18.8 & 20.6 \\
\hline Depression & 95 & 14.0 & 210 & 19.0 & 17.1 \\
\hline Asthma & 94 & 13.8 & 174 & 15.8 & 15.0 \\
\hline Heart Disease & 134 & 19.7 & 113 & 10.2 & 13.9 \\
\hline Diabetes & 117 & 17.2 & 99 & 9.0 & 12.1 \\
\hline Stroke & 37 & 5.4 & 39 & 3.5 & 4.3 \\
\hline
\end{tabular}

${ }^{\mathrm{a} S t a n d a r d}$ Deviations inflated for clustering within practice

${ }^{\mathrm{b}}$ As defined by the Office of National

Statistics (http://www.ons.gov.uk/ons/guide-method/classifications/current-standard-classifications/soc2010/soc2010-volume-3-ns-sec-rebased-on-soc2010-usermanual/index.html)

professional occupations (42.8\%). The most common self-reported health conditions were 'other' (29.2\%), 'backache' (28.7 \%) and 'arthritis' (23.8 \%).

There were two significant associations in reported health conditions between men and women, with men showing significantly higher rates of both heart disease (19.7 and $10.2 \%, p<0.001)$ and diabetes $(17.2$ and $9.0 \%$, $p<0.001)$.

\section{Screening: eligibility for interventions based on current recommendations}

$24.2 \%$ of participants reported levels that would trigger intervention for one health behaviour only [Table 2]. The majority screened positive for two risky behaviours (43.6\%). Out of 2066 participants, only $4.5 \%$ did not screen positive for any of the risk behaviours.

Where patients screened positive for single health behaviours only [Table 3], the majority screened positive for low levels of exercise (12.0\% of all combinations) which was substantially more than those who screened positive for the next most common single health behaviour, diet $(8.7 \%)$. The numbers who screened positive for alcohol and smoking individually were substantially lower again at 2.8 and $0.7 \%$ respectively.

Where behaviours co-occurred, diet and exercise were most common with $27.2 \%$ screening positive for these

Table 2 Screening patterns for risky health behaviours

\begin{tabular}{|c|c|c|c|c|c|}
\hline \multirow[t]{2}{*}{ Behaviours } & \multicolumn{2}{|c|}{$\begin{array}{l}\text { Male } \\
(N=787)\end{array}$} & \multicolumn{2}{|c|}{$\begin{array}{l}\text { Female } \\
(N=1279)\end{array}$} & \multirow{2}{*}{$\begin{array}{l}\text { Overall } \\
(N=2066) \\
\%\end{array}$} \\
\hline & $\bar{N}$ & $\%$ & $\mathrm{~N}$ & $\%$ & \\
\hline No Behaviours & 37 & 4.7 & 56 & 4.4 & 4.5 \\
\hline One health behaviour & 197 & 25.0 & 303 & 23.7 & 24.2 \\
\hline Two health behaviours & 331 & 42.0 & 570 & 44.7 & 43.6 \\
\hline Three health behaviours & 177 & 22.5 & 273 & 21.4 & 21.8 \\
\hline All four health behaviours & 45 & 5.7 & 77 & 6.0 & 5.9 \\
\hline
\end{tabular}

Number and proportion of participants with one or more adverse health behaviours 
Table 3 Screening patterns for single and co-occurring risky health behaviours

\begin{tabular}{|c|c|c|c|c|c|c|}
\hline \multirow{2}{*}{$\begin{array}{l}\text { No. of } \\
\text { behaviours }\end{array}$} & \multirow[t]{2}{*}{ Behaviours } & \multicolumn{2}{|c|}{ Male $(N=787)$} & \multicolumn{2}{|c|}{ Female $(N=1279)$} & \multirow{2}{*}{$\begin{array}{l}\text { Overall }(N=2066) \\
\%\end{array}$} \\
\hline & & $\bar{N}$ & $\%$ & $\overline{\mathrm{N}}$ & $\%$ & \\
\hline 0 & No Behaviours & 37 & 4.7 & 56 & 4.4 & 4.5 \\
\hline \multirow[t]{4}{*}{1} & Exercise only & 70 & 8.9 & 178 & 13.9 & 12.0 \\
\hline & Diet only & 97 & 12.0 & 83 & 6.5 & 8.7 \\
\hline & Alcohol only & 26 & 3.3 & 32 & 2.5 & 2.8 \\
\hline & Smoking only & 4 & 0.5 & 10 & 0.8 & 0.7 \\
\hline \multirow[t]{6}{*}{2} & Diet and Exercise & 195 & 25.0 & 367 & 28.7 & 27.2 \\
\hline & Alcohol and Diet & 79 & 10.0 & 56 & 4.4 & 6.5 \\
\hline & Alcohol and Exercise & 22 & 2.8 & 80 & 6.3 & 4.9 \\
\hline & Diet and Smoking & 20 & 2.5 & 32 & 2.5 & 2.5 \\
\hline & Alcohol and Smoking & 9 & 1.1 & 11 & 0.9 & 1.0 \\
\hline & Exercise and Smoking & 6 & 0.8 & 24 & 1.9 & 1.5 \\
\hline \multirow[t]{4}{*}{3} & Alcohol, Diet and Exercise & 96 & 12.0 & 143 & 11.2 & 11.6 \\
\hline & Diet, Exercise and Smoking & 37 & 4.7 & 75 & 5.9 & 5.4 \\
\hline & Alcohol, Diet and Smoking & 33 & 4.2 & 31 & 2.4 & 3.1 \\
\hline & Alcohol, Exercise and Smoking & 11 & 1.4 & 24 & 1.9 & 1.7 \\
\hline \multirow[t]{5}{*}{4} & Alcohol, Diet, Exercise \& Smoking & 45 & 5.7 & 77 & 6.0 & 5.9 \\
\hline & Alcohol & 321 & 40.8 & 454 & 35.5 & 37.5 \\
\hline & Diet & 602 & 76.5 & 864 & 67.6 & 70.9 \\
\hline & Exercise & 482 & 61.2 & 968 & 75.7 & 70.1 \\
\hline & Smoking & 165 & 21.0 & 284 & 22.2 & 21.7 \\
\hline
\end{tabular}

behaviours. Thus $47.9 \%$ did not attain recommended guidelines for diet and exercise either alone or combined - (diet only $8.7 \%$, exercise only $12.0 \%$, combined $27.2 \%$ ). Out of 16 possible combinations of health behaviours [Table 3], 5 combinations made up of 3 behaviours accounted for the majority screened positive for (66.0 \%) - [Diet and Exercise], [Exercise only], [Alcohol, Diet and Exercise], [Diet only], [Alcohol and Diet]. Diet and exercise were most common being in 4 and 3 out of 5 of the groups respectively. There were significant associations with gender in 3 of these categories - Exercise only (males $8.9 \%$, females $13.9 \%, p=0.001$ ), Diet only (males $12.0 \%$, females $6.5 \%, p<0.001$ ), Alcohol and Diet (males $10.0 \%$, females $4.4 \%, p<$ 0.001). There were also significant associations in Alcohol and Exercise (males $2.8 \%$, females $6.3 \%, p<$ 0.001), and Alcohol, Diet and Smoking (males $4.2 \%$, females $2.4 \%, p=0.026$ ). There was no significant association between genders when screening individually for Alcohol (males $3.3 \%$, females $2.5 \%, p=0.337$ ) and Smoking (males $0.5 \%$, females $0.8 \%, p=0.586$ ).

The results of the ordinal regressions [Table 4] indicated that:

1. For a unit increase in age, the odds of $0,1,2$ and 3 risky behaviours, in comparison to 4 risky behaviours, are 0.977 greater, i.e. for a unit increase in age, it is $2.3 \%$ less likely to have $0,1,2$ and 3 risky behaviours in comparison to 4 risky behaviours;

2. For Males, the odds of 0,1, 2 and 3 risky behaviours, in comparison to 4 risky behaviours, are 1.270 greater than females, i.e. for males, it is $27.0 \%$ more likely to have $0,1,2$ and 3 risky behaviours in comparison to 4 risky behaviours than females;

3. Marital status is not predictive of number of risky behaviours;

4. For those in non-Managerial/Professional Occupations, the odds of $0,1,2$ and 3 risky behaviours, in comparison to 4 risky behaviours, are 1.269 greater than those in Managerial/Professional Occupations, i.e. for those in non-Managerial/ Professional Occupations, it is $26.9 \%$ more likely to have $0,1,2$ and 3 risky behaviours in comparison to 4 risky behaviours than those in Managerial/ Professional Occupations;

5. Number of health conditions is not predictive of number of risky behaviours.

Multi-level and simple ordinal regressions produced similar results, meaning that there was minimal clustering in patterns of screening based on practice. 
Table 4 Ordinal regression results

\begin{tabular}{|c|c|c|c|c|c|c|c|}
\hline \multirow[t]{2}{*}{ Variable } & & \multicolumn{3}{|l|}{ Simple } & \multicolumn{3}{|l|}{ Multilevel } \\
\hline & & $\begin{array}{l}\text { Proportional } \\
\text { odds ratio }\end{array}$ & $\begin{array}{l}95 \% \text { confidence } \\
\text { interval }\end{array}$ & $\overline{p \text {-value }}$ & $\begin{array}{l}\text { Proportional } \\
\text { odds ratio }\end{array}$ & $\begin{array}{l}95 \% \text { confidence } \\
\text { interval }\end{array}$ & $p$-value \\
\hline \multicolumn{2}{|l|}{ Age } & 0.977 & $0.971-0.983$ & $<0.001$ & 0.977 & $0.971-0.983$ & $<0.001$ \\
\hline \multirow[t]{2}{*}{ Gender } & Male & 1.270 & $1.045-1.543$ & 0.016 & 1.270 & $1.042-1.548$ & 0.018 \\
\hline & Female & (Reference) & & & (Reference) & & \\
\hline \multirow[t]{2}{*}{ Marital Status } & Single/divorced/widowed & 1.084 & $0.891-1.319$ & 0.422 & 1.084 & $0.890-1.320$ & 0.424 \\
\hline & Married/cohabiting & (Reference) & & & (Reference) & & \\
\hline \multirow[t]{2}{*}{ Occupation } & All other occupations & 1.269 & $1.047-1.528$ & 0.015 & 1.269 & $1.044-1.543$ & 0.017 \\
\hline & $\begin{array}{l}\text { Managerial and professional } \\
\text { occupations }\end{array}$ & (Reference) & & & (Reference) & & \\
\hline \multicolumn{2}{|c|}{ Number of health conditions (1-11) } & 1.050 & $0.984-1.120$ & 0.139 & 1.050 & $0.982-1.122$ & 0.152 \\
\hline
\end{tabular}

Note that ' 4 risky behaviours' is the reference category, so the proportional odds ratio relates to how much more likely the patient is to have either $0,1,2$ or 3 risky behaviours in comparison to 4 risky behaviours

\section{Discussion}

\section{Summary}

Almost all adult individuals consulting for routine primary care screened eligible for an intervention about risky health related behaviours, and these behaviours tend to cluster together within individuals. The vast majority failed to achieve recommended threshold levels for both diet and exercise in particular. This study found a consistent socio-demographic gradient in the prevalence of multiple risk factors, with women, older age groups and those in managerial or professional occupations being more likely to exhibit all four risky health behaviours.

\section{Comparison with existing literature}

This study found patterns in the prevalence of risk factors to be in line with previous research [12-15] therefore supporting evidence that screening in primary care should be targeted to efficiently address multiple as opposed to single health behaviours $[30,31]$ in those most at risk. Those with particular health conditions for example, cardiovascular disease or diabetes, may be more effectively assessed as potentially benefitting from intervention.

\section{Limitations}

Consideration must be given to the practicality and impact of trying to implement screening and interventions. Due to the competing demands and time constraints experienced by clinicians in primary care $[32,33]$ coupled with a lack of confidence [30] and knowledge [34, 35] in being able to provide brief advice [36], routine screening may often be overlooked. As well, a lack of alternative services to refer patients to may deter clinicians from raising discussions about health behaviours in the first place.
A limitation of this study is its sample which was a subset of patients attending primary care who could speak English and who were willing to participate in a randomised controlled trial. In addition, there was a risk of selection bias as a result the relatively small sample which was confined to those attending a limited number of GP practices in South Wales. Another recognised weakness comes with the use of self-report measures for health behaviours. It is likely that more individuals are actually at risk than were identified as there is an evidenced tendency to over report levels of physical activity [37] and healthy eating [38] and under report levels of smoking [39].

\section{Implications for research and practice}

In this study, screening was completed by the research team prior to patients going into their appointment. In presenting the clinician with a ready summary of exceeded thresholds, it was immediately clear which areas might be of benefit to discuss with the patient therefore relieving some of the pressure on their time [40]. This is obviously not reflective of everyday practice so looking at practical ways of utilising waiting time as well as capitalising on the roles of reception staff and nurses for implementing screening could have a significant impact on making it more achievable [41].

It is also worth reflecting on the use of the 'gold standard' screening tools - that is those deemed to be the benchmark by which outcomes are measured - currently being used in primary care and whether they are still the most appropriate in light of the evidence around co-occurrence. This study used a combination of these which are designed for single health behaviours. The study team were on hand to provide patients with these forms and be of assistance during the screening process if required, however this wouldn't be viable for practice. 
The tools can be quite confusing and time consuming to complete. Evidence from focus groups in primary care show that shorter, easy to score screening instruments are more likely to be used with questions relating to general health and lifestyle being less stigmatizing and received better by patients [42]. Further research needs to focus on developing gold standard brief screening tools for multiple health behaviours.

Clinicians also need more guidance on how to then intervene with patients. Seale et al. [43] suggest that clinicians already providing advice on one health behaviour might actually find it easier to address a second at the same time. They need to be able to identify which behaviours are going to be most appropriate to target effectively with the potential for a kind of 'spill-over' from one intervention influencing a co-occuring unhealthy behaviour. Increasingly, research is showing that multiple unhealthy behaviours can be changed simultaneously though exactly how this might be tackled is still not clear [44]. What is apparent is that individuals who have already been successful in changing one risky health behaviour may be able to transfer that success to a second behaviour [45] though greater effects may be achieved when intervening for particular pairings of unhealthy behaviours such as physical activity and healthy eating [41]. The effectiveness of an intervention will not only depend on highlighting unhealthy behaviours but also patients' readiness to change $[40,46]$.

\section{Conclusion}

When undertaking screening in primary care, very few patients would screen ineligible for any intervention using current screening tools. Clinicians might reasonably expect to see risky health behaviours occur together in an individual, especially in pairs of behaviours with diet and exercise most commonly occurring. There are still many challenges in the detection of unhealthy behaviours in primary care and in the delivery of anticipatory care associated with them. Findings from this study add to current knowledge on screening patterns of risky health behaviours and multiple risk behaviours in primary care. The need to look at how to best identify those at risk as well as the practicalities of who is best placed to do this has also been identified. Instruments better suited to identifying multiple risky health behaviours need to be researched as well as ways in which clinicians can be supported to deliver screening. With more effective screening comes the need to establish effective interventions which are geared towards tackling multiple risky health behaviours.

\footnotetext{
Abbreviations

AUDIT-C: Alcohol Use Disorders Identification Test Consumption;

COPD: Chronic Obstructive Pulmonary Disease; DINE: Dietary Instrument for

Nutrition Education; HSI: Heaviness of Smoking Index; IPAQ: International

Physical Activity Questionnaire; WHO: World Health Organisation.
}

\section{Competing interests}

The authors declare that they have no competing interests in relation to this study.

\section{Authors' contributions}

ER led the writing of this manuscript and contributed to data collection. TP led the statistical analysis. SAS contributed to the trial design, funding application, trial implementation and the intervention development. CS contributed to the protocol and intervention development, managed the trial and led the intervention delivery. JMC contributed to the study design and management. $\mathrm{KH}$ contributed to the study design, management and led the statistical component of the main trial results. CCB was the Principal Investigator who conceived the study and led the study design and funding application. All authors contributed to, read and approved the final version of the manuscript.

\section{Acknowledgements}

The authors would like to acknowledge the funder of this study: the National Prevention Research Initiative http://www.mrc.ac.uk/research/initiatives/ national-prevention-research-initiative-npri/ with support from the following organisations: British Heart Foundation; Cancer Research UK; Chief Scientist Office, Scottish Government Health Directorate; Department of Health; Diabetes UK; Economic and Social Research Council; Health \& Social Care Research \& Development Office for Northern Ireland; Medical Research Council; Welsh Assembly Government; and World Cancer Research Fund (NPRI, G0501283). The International Standard Randomised Controlled Trial Number assigned by the Medical Research Council is 22495456. The authors would also like to acknowledge the contribution of the Trial Steering Committee members, namely Dr Molly Byrne, Dr Tim Coleman, Dr Amanda Farrin, Dr Marlie Ferenczi and Mr Greg Morgan. A special thanks to Miss Aude Espinasse, the Study Administrator. Finally acknowledgments are due to the study participants, both clinicians and patients.

\section{Author details}

${ }^{1}$ South East Wales Trials Unit, Centre for Trials Research, Cardiff University, 7th floor Neuadd Meirionnydd, Heath Park, Cardiff CF14 4YS, UK. ${ }^{2}$ MRC/CSO SPHSU, 200 Renfield Street, Glasgow G2 3QB, UK. ${ }^{3}$ School of Psychology, Faculty of Health \& Social Sciences, University of Bedfordshire, Park Square, Luton LU1 3JU, UK. ${ }^{4}$ Department of Health Sciences, Seebohm Rowntree Building University of York, Heslington, York YO10 5DD, UK. ${ }^{5}$ Nuffield Department of Primary Care Health Sciences, University of Oxford, New Radcliffe House, Radcliffe Observatory Quarter, Woodstock Road, Oxford OX2 6NW, UK.

Received: 13 April 2015 Accepted: 6 October 2015

Published online: 09 October 2015

\section{References}

1. Alwan AD, Galea G, Stuckler D. Development at risk: addressing noncommunicable diseases at the United Nations high-level meeting. Bull World Health Organ. 2011;89(8):546-A.

2. Organisation WH. Global status report on noncommunicable diseases 2010. 2010.

3. Goldstein MG, Whitlock EP, DePue J. Multiple behavioral risk factor interventions in primary care. Summary of research evidence. Am J Prev Med. 2004;27(2 Suppl):61-79.

4. Welsh Health Survey. 2013. Accessed 23/03/2015. http://gov.wales/statisticsand-research/welsh-health-survey/?tab=previous\&lang=en.

5. Emmons KM, Marcus BH, Linnan L, Rossi JS, Abrams DB. Mechanisms in multiple risk factor interventions: smoking, physical activity, and dietary fat intake among manufacturing workers. Working Well Research Group. Prev Med. 1994;23(4):481-9.

6. Conway TL, Cronan TA. Smoking, exercise, and physical fitness. Prev Med. 1992;21(6):723-34.

7. Kranzler HR, Amin H, Cooney NL, Cooney JL, Burleson JA, Petry N, et al. Screening for health behaviors in ambulatory clinical settings: does smoking status predict hazardous drinking? Addict Behav. 2002;27(5):737-49.

8. Shah M, French SA, Jeffery RW, McGovern PG, Forster JL, Lando HA. Correlates of high fat/calorie food intake in a worksite population: the Healthy Worker Project. Addict Behav. 1993;18(5):583-94. 
9. Stevens G, Mascarenhas M, Mathers C. Global health risks: progress and challenges. Bull World Health Organ. 2009;87(9):646.

10. Prochaska JJ, Nigg CR, Spring B, Velicer WF, Prochaska JO. The benefits and challenges of multiple health behavior change in research and in practice. Prev Med. 2010;50(1-2):26-9.

11. Buck D, Frosini F. Clustering of unhealthy behaviours over time: Implications for policy and practice. The King's Fund. 2012. August 2012. Report No.

12. Poortinga $W$. The prevalence and clustering of four major lifestyle risk factors in an English adult population. Prev Med. 2007;44(2):124-8.

13. Schuit AJ, van Loon AJ, Tijhuis M, Ocke M. Clustering of lifestyle risk factors in a general adult population. Prev Med. 2002;35(3):219-24.

14. Berrigan D, Dodd K, Troiano RP, Krebs-Smith SM, Barbash RB. Patterns of health behavior in U.S. adults. Prev Med. 2003;36(5):615-23.

15. Chiolero A, Wietlisbach V, Ruffieux C, Paccaud F, Cornuz J. Clustering of risk behaviors with cigarette consumption: a population-based survey. Prev Med. 2006:42(5):348-53.

16. Walker A, Maher J, Coulthard M, Goddard E, Thomas M. Living in Britain. Results from the 2000 General Household Survey. London: The Stationary Office, 2001.

17. Brotons C, Drenthen AJ, Durrer D, Moral I, European Network on P, Health P. Beliefs and attitudes to lifestyle, nutrition and physical activity: the views of patients in Europe. Fam Pract. 2012;29 Suppl 1:i49-55.

18. Hippisley-Cox JVY. Trends in Consultation Rates in General Practice 1995/ 1996 to 2008/2009: Analysis of the QResearch database. Final Report to the NHS Information Centre and Department of Health. London: The Information Centre; 2009.

19. Ampt AJ, Amoroso C, Harris MF, McKenzie SH, Rose VK, Taggart JR. Attitudes, norms and controls influencing lifestyle risk factor management in general practice. BMC Fam Pract. 2009;10:59

20. Wilson GB, Lock CA, Heather N, Cassidy P, Christie MM, Kaner EF. Intervention against excessive alcohol consumption in primary health care: a survey of GPs' attitudes and practices in England 10 years on. Alcohol Alcohol. 2011;46(5):570-7.

21. Mokdad AH, Marks JS, Stroup DF, Gerberding JL. Actual causes of death in the United States, 2000. JAMA. 2004;291(10):1238-45.

22. Watt G, O'Donnell C, Sridharan S. Building on Julian Tudor Hart's example of anticipatory care. Prim Health Care Res Dev. 2011;12(1):3-10.

23. National Institue for Clinical Excellence. Prevention of cardiovascular disease. NICE public health guidance 25. Issued: June 2010. Retrieved from http://www.nice.org.uk/guidance/ph25/resources/guidance-prevention-ofcardiovascular-disease-pdf. Accessed 23/03/2015

24. Spanou C, Simpson SA, Hood K, Edwards A, Cohen D, Rollnick S, et al. Preventing disease through opportunistic, rapid engagement by primary care teams using behaviour change counselling (PRE-EMPT): protocol for a general practice-based cluster randomised trial. BMC Fam Pract. 2010;11:69.

25. Kozlowski LT, Porter CQ, Orleans CT, Pope MA, Heatherton T. Predicting smoking cessation with self-reported measures of nicotine dependence: FTQ, FTND, and HSI. Drug Alcohol Depend. 1994;34(3):211-6.

26. Bush K, Kivlahan DR, McDonell MB, Fihn SD, Bradley KA. The AUDIT alcohol consumption questions (AUDIT-C): an effective brief screening test for problem drinking. Ambulatory Care Quality Improvement Project (ACQUIP). Alcohol Use Disorders Identification Test. Arch Intern Med. 1998;158(16):1789-95.

27. Craig CL, Marshall AL, Sjostrom M, Bauman AE, Booth ML, Ainsworth BE, et al. International physical activity questionnaire: 12-country reliability and validity. Med Sci Sports Exerc. 2003;35(8):1381-95.

28. Cappuccio FP, Rink E, Perkins-Porras L, McKay C, Hilton S, Steptoe A. Estimation of fruit and vegetable intake using a two-item dietary questionnaire: a potential tool for primary health care workers. Nutr Metab Cardiovasc Dis. 2003;13(1):12-9.

29. Roe L, Strong C, Whiteside C, Neil A, Mant D. Dietary intervention in primary care: validity of the DINE method for diet assessment. Fam Pract. 1994;11(4):375-81.

30. Strecher V, Wang C, Derry H, Wildenhaus K, Johnson C. Tailored interventions for multiple risk behaviors. Health Educ Res. 2002;17(5):619-26.

31. Yarnall KS, Pollak Kl, Ostbye T, Krause KM, Michener JL. Primary care: is there enough time for prevention? Am J Public Health. 2003;93(4):635-41.

32. Rollnick S, Mason P, Butler C. Health behaviour change: a guide for practitioners. Edinburgh, UK: Churchill Livingstone; 1999.
33. Crabtree BF, Miller WL, Tallia AF, Cohen DJ, DiCicco-Bloom B, Mcllvain HE, et al. Delivery of clinical preventive services in family medicine offices. Ann Fam Med. 2005;3(5):430-5.

34. Phillips K, Wood F, Spanou C, Kinnersley P, Simpson SA, Butler CC, et al. Counselling patients about behaviour change: the challenge of talking about diet. Br J Gen Pract. 2012;62(594):e13-21.

35. Chisholm A, Hart J, Lam V, Peters S. Current challenges of behavior change talk for medical professionals and trainees. Patient Educ Couns. 2012;87(3):389-94.

36. Friedmann PD, McCullough D, Chin MH, Saitz R. Screening and intervention for alcohol problems. A national survey of primary care physicians and psychiatrists. J Gen Intern Med. 2000;15(2):84-91.

37. Rzewnicki R, Vanden Auweele Y, De Bourdeaudhuij I. Addressing overreporting on the International Physical Activity Questionnaire (IPAQ) telephone survey with a population sample. Public Health Nutr. 2003;6(3):299-305.

38. Richardson DCN, Roberts K, Ells L. Measuring diet and physical activity in weight management interventions: abriefing paper. Oxford: National Obesity Observatory; 2011.

39. Connor Gorber S, Schofield-Hurwitz S, Hardt J, Levasseur G, Tremblay M. The accuracy of self-reported smoking: a systematic review of the relationship between self-reported and cotinine-assessed smoking status. Nicotine Tob Res. 2009;11(1):12-24.

40. Butler CC, Simpson SA, Hood K, Cohen D, Pickles T, Spanou C, et al. Training practitioners to deliver opportunistic multiple behaviour change counselling in primary care: a cluster randomised trial. BMJ. 2013;346:f1191.

41. Goodyear-Smith F, Warren J, Elley CR. The eCHAT program to facilitate healthy changes in New Zealand primary care. J Am Board Fam Med. 2013;26(2):177-82.

42. Coulton S, Perryman K, Bland M, Cassidy P, Crawford M, Deluca P, et al. Screening and brief interventions for hazardous alcohol use in accident and emergency departments: a randomised controlled trial protocol. BMC Health Serv Res. 2009;9:114

43. Seale JP, Shellenberger S, Velasquez MM, Boltri JM, Okosun I, Guyinn M, et al. Impact of vital signs screening \& clinician prompting on alcohol and tobacco screening and intervention rates: a pre-post intervention comparison. BMC Fam Pract. 2010;11:18.

44. Yin HQ, Prochaska JO, Rossi JS, Redding CA, Paiva AL, Blissmer B, et al. Treatment-enhanced paired action contributes substantially to change across multiple health behaviors: secondary analyses of five randomized trials. Transl Behav Med. 2013;3(1):62-71.

45. Paiva AL, Prochaska JO, Yin HQ, Rossi JS, Redding CA, Blissmer B, et al. Treated individuals who progress to action or maintenance for one behavior are more likely to make similar progress on another behavior: coaction results of a pooled data analysis of three trials. Prev Med. 2012;54(5):331-4.

46. Cohen DJ, Balasubramanian BA, Isaacson NF, Clark EC, Etz RS, Crabtree BF. Coordination of health behavior counseling in primary care. Ann Fam Med. 2011;9(5):406-15.

\section{Submit your next manuscript to BioMed Central and take full advantage of:}

- Convenient online submission

- Thorough peer review

- No space constraints or color figure charges

- Immediate publication on acceptance

- Inclusion in PubMed, CAS, Scopus and Google Scholar

- Research which is freely available for redistribution

Submit your manuscript at www.biomedcentral.com/submit 